\title{
Quen guarda, faya. Aproximación a los refranes mínimos asturianos*
}

\author{
JoAn Fontana i Tous \\ UNIVERSITAT DE BARCELONA \\ joan_fontana@ub.edu
}

Recibido: 23/04/2018

Aceptado: 22/10/2018

\section{RESUMEN:}

Entendemos como refrán mínimo la unidad paremiológica con sentido pleno, formulada con verbo explícito o bien elidido, y que se enuncia con el mínimo número posible de componentes. En este sentido, el artículo pretende ofrecer, dentro del ámbito romance, un primer corpus de trabajo de refranes mínimos en asturiano, obtenido a partir de los refraneros de Castañón (1962), ampliado con dos apéndices (1963 y 1965), Martino (2008), Viejo (2012) y Sánchez y Cañedo (2012). De dicho corpus, conformado por 38 refranes mínimos asturianos, se analizarán las cuatro paremias compuestas por dos únicos elementos y, asimismo, se buscarán estructuras recurrentes en los 34 refranes mínimos constituidos por tres elementos.

PALABRAS CLAVE: refrán mínimo, lengua asturiana, paremiología, lenguas romances.

Quen guarda, faya. Approximation to minimal Asturian proverbs

\section{ABSTRACT:}

A minimal proverb is a paremiological unit with full meaning, formulated with an explicit or elided verb, and stated with the minimum number of components. The aim of this article is to offer a first corpus of minimal proverbs in Asturian, obtained from the following books of popular sayings: Castañón (1962), expanded with two appendi- 
ces (1963 and 1965), Martino (2008), Viejo (2012) and Sánchez and Cañedo (2012). In this corpus of 38 minimal Asturian proverbs, we analyze the four paroemias composed of two single elements, and examine some recurrent structures in the 34 minimal proverbs comprising three elements.

KEYWORDS: Minimal proverb, Asturian language, Paremiology, Romance languages.

\section{Introducción}

Si nos preguntaran cuál fue el primer refrán asturiano que oímos, nuestra respuesta no se haría esperar: ¿Casástete? Cagástete ${ }^{1}$. Dejando a un lado la, para muchos, sabia admonición que contiene dicha paremia, lo que más nos sorprendió fue la inusitada capacidad de condensar su lección moral en tan solo dos elementos². Nuestra admiración aumentó cuando, años más tarde, descubrimos en Castañón (1962: 59) la equivalencia, según él «valenciana», a la citada paremia: Yá t'as casat, ya t'as cagat (sic) ${ }^{3}$; refrán que, en su forma más habitual, T'has casat, t’has cagat (Farnés, 1993: II, 868, núm. C1779), prescinde del adverbio inicial ${ }^{4}$ en ambos hemistiquios $\mathrm{y}$, por tanto, coincide con el original asturiano. El hecho de

\footnotetext{
* Agradezco a Ramón d'Andrés, a Joan Fontana i Figuerola y a José Enrique Gargallo Gil sus siempre ponderados y valiosos consejos.

1 Concretamente, fue durante una entrañable conversación con la familia Argüelles en Bañugues el 8 de agosto del año 2000.

2 No en balde, los refranes también se denominan evangelios abreviados o chicos (cfr. DLE, s. v. evangelio). En esta dirección, Castañón (1981: 256) afirma: «El pueblo toma de los refranes ciertas normas para su vida, pues los considera totalmente ciertos e infalibles, llegando a llamarlos «evangelios chicos» o abreviados, estando afianzados en la experiencia de muchas generaciones, y aun algunos de siglos».

3 Castañón (1965: 99) recoge en Puertas de Vidiago (Llanes) la paremia Ya te casesti, ya te abrasesti. El mismo autor la retoma en una obra posterior (1981: 264), esta vez sin indicación geográfica.

4 Farnés cita la versión de Castañón en la tercera variante: Ja t’has casat ja t'has cagat. Por su parte, Amades $\left(1982^{3}: 1108\right)$ engarza este refrán con otro que no hace más que redundar en la idea sugerida: Qui es casa es caga; ja t'has casat, ja t'has cagat.
} 
que en catalán la paremia conste de seis elementos ${ }^{5}$, en contraste con los dos del asturiano, obedece a tres criterios distintos y, sin embargo, complementarios: el morfológico (a diferencia del tiempo de pasado sintético del asturiano, el catalán se decanta por el uso de uno analítico: has casat y has cagat), el ortográfico (mientras que el asturiano añade el pronombre a la forma verbal sin guion, el catalán apostrofa dicho pronombre delante del auxiliar verbal: t'has) y el pragmático (en catalán se podría haber recurrido al tiempo sintético de pasado: casares, cagares ${ }^{6}$; no obstante, esta combinación carece de tradición paremiológica).

A tenor de lo anteriormente expuesto, proponemos la denominación refrán mínimo (refrán mínimu, en asturiano) para designar la unidad paremiológica con sentido pleno, formulada con verbo explícito o bien elidido, y que se enuncia con el mínimo número posible de componentes. En este sentido, como subrayamos en el párrafo precedente, tanto las características morfológicas (pensemos en la ya mencionada tipología de los tiempos verbales, sintéticos o analíticos), ortográficas (recordemos el uso del guion y el apóstrofo), como pragmáticas (el empleo de un tiempo analítico en vez de uno sintético, en lenguas que disponen de ambas posibilidades, como el ya citado catalán) determinarán que no se pueda establecer un mismo número «canónico» de elementos constitutivos para los refranes mínimos de las diversas lenguas. Sentadas estas premisas, el presente artículo intentará determinar las principales características de un primer corpus de refranes mínimos asturianos.

5 En el caso del español, la anteposición de los pronombres (te y la) da lugar a una paremia de cuatro elementos, Te casaste, la cagaste (Martínez, 1995: 454, núm. 39.651), a medio camino entre el refrán asturiano (de dos elementos) y el catalán (de seis).

6 Aunque Castañón (1962: 59) etiquete como «valenciana» una paremia formulada con la variante analítica del tiempo verbal, cabe apuntar que el valenciano central, o apitxat, se caracteriza precisamente por el uso de la forma sintética (casares en vez de has casat y cagares en lugar de has cagat); cfr. Veny (1982 $\left.{ }^{3}: 170\right)$. 


\section{Refranes mínimos}

Baste el ejemplo citado en la introducción, ¿Casástete? Cagástete, como muestra fehaciente de que el asturiano posee refranes mínimos compuestos por dos elementos; ; concretamente, hemos localizado cuatro, que analizaremos brevemente para pasar, a renglón seguido, a los 34 refranes mínimos constituidos por tres elementos. En este caso, por razones de espacio, no nos podremos detener a comentar cada uno de los ejemplos ${ }^{8}$, si bien analizaremos las estructuras más recurrentes en este tipo de paremias.

Para la elaboración del corpus de refranes mínimos, tanto de dos como de tres elementos, que se presenta ordenado alfabéticamente en el Apéndice, hemos vaciado los refraneros de Castañón (1962)', ampliado con dos apéndices (Castañón, 1963 y 1965), Martino (2008), Viejo (2012) y Sánchez y Cañedo (2012) Las paremias extraídas de dichas fuentes se han complementado con otras obras, como el DGLA, en primer lugar.

7 Refranes de un único elemento resultan imposibles puesto que la formulación parémica adquiere sentido a través de la relación de oposición, consecuencia, resultado... que vincula ambos elementos.

8 Todos los refranes se reúnen en un Apéndice final que incluye su traducción, así como las diferentes informaciones (glosas, notas...) presentes en las fuentes bibliográficas consultadas.

9 Es curioso constatar que, en los 120 refranes asturianos que Castañón nos aporta como «breve anticipo del Rrefranero [sic] asturiano» de 1962 (Castañon, 1959: 449), no hallamos ningún refrán mínimo.

10 No hemos calificado arbitrariamente de «aproximación» el presente artículo, ya que resulta evidente que el corpus de refranes mínimos presentado aquí puede ampliarse en cualquier momento gracias a fuentes orales o bien a monografías escritas. En este sentido, pensamos en trabajos como el de Álvarez (1963), dedicado al habla y a la cultura popular de Cabrales, que contiene un, no por breve poco importante, apartado paremiológico. 
Refranes mínimos constituidos por dos elementos

(I) Abogáu, afogáu ['Abogado, ahogado']

Con idéntica formulación en las cuatro fuentes que lo recogen ${ }^{11}$ : DGLA (s. v. abogáu y afogáu), Martino (2008: 61 y 193), Viejo (2012: 388, núm. 3135) y Sánchez y Cañedo (2012: 100, núm. 783). Esta paremia, síntesis de una posible estructura más amplia que se puede glosar como «El abogado como mejor está es ahogado», resume a la perfección el sentir del acervo asturiano, y no solo de éste ${ }^{12}$, respecto al «pecaminoso» oficio de la abogacía ${ }^{13}$ : Cuando toma cuerpu'l Pecáu, vístese d'abogáu ${ }^{14}$ ['Cuando toma cuerpo el Pecado, se viste de abogado'] (Viejo, 2012: 260, núm. 1610) o Naide fue al abogáu, que nun volviera tosquiláu ${ }^{15}$

11 Cuando una paremia se ha extraído de dos o más fuentes, éstas se citan en orden cronológico.

12 Cfr., por ejemplo, una recurrente formulación parémica en español, Buen abogado, mal cristiano (Martínez, 1995: 2, núm. 82); en catalán, Bon advocat, mal cristià (Parés, 2000: 367, núm. 1245); o en italiano, Grande avvocato, cattivo cristiano (Lapucci, 2007: 126, núm. 1701). A título anecdótico, Quevedo, en su libro La fortuna con seso y la hora de todos, fantasía moral, «llamó «Peralvillo de las bolsas» al estudio de un abogado ignorante y embrollón, porque en el bufete de aquel letrado daban fin las bolsas de los litigantes, del mismo modo que en Peralvillo encontraban la muerte los ladrones y malhechores» (Iribarren, 19744: 396). Aclaremos que Peralvillo alude al pueblo de la provincia de Ciudad Real donde el tribunal de la Santa Hermandad juzgaba sumarísimamente y ejecutaba a los delincuentes que cometían crímenes en despoblado; de donde la expresión La justicia de Peralvillo.

13 Para un seguimiento más exhaustivo de la figura del abogáu en el refranero asturiano, cfr. DGLA (s. v. abogáu), Martino (2008: 69, 71, 74 y 194), Viejo (2012: 275, núm. 1782; 287, núm. 1912; 302, núm. 2080; 308, núm. 2149) y Sánchez y Cañedo (2012: 100, núm. 814; 132, núm. 2079).

14 Con pecáu en vez de Pecáu, en Martino (2008: 193) y Sánchez y Cañedo (2012: 801, núm. 100). Asimismo, con pecáu y sin coma, en DGLA (s. v. abogáu); con la formulación cuerpu el Pecáu, y sin coma, en DGLA (s. v. pecáu). Compárese con el refrán castellano Cuando toma cuerpo el diablo, se disfraza de abogado (Etxabe, 2001: 102), así como con el gallego Cando toma corpo o diaño, vístese de abogado (Ferro, 1995: 115, núm. 1271).

15 Sin coma entre hemistiquios, en Martino (2008: 75 y 195) y Sánchez y Cañedo (2012: 101, núm. 834). Esta paremia nos recuerda la siguiente versión friulana: Cui 
['Nadie fue al abogado que no volviera trasquilado'] (Viejo, 2012: 339, núm. 2515).

(II) «Aguaza», jatraca! ${ }^{16}$

Refrán marinero recogido por Castañón (1962: 21) y el DGLA (s. v. aguaza), obra que, a su vez, remite al primer autor. Aunque el substantivo aguaza aparezca en el DGLA (s. v. aguaza) y en Sánchez (2008, s. v. aguaza) como «Plancton de agua marina», Castañón nos aclara que, en este caso, se trata de «manchas verdosas ${ }^{[17]}$ en el mar, en las cuales hay abundancia de sardina», dado que a tales manchas estos peces «se atracan o aproximan" ${ }^{18}$ (Saralegui, 1917: 173, núm. 314) a fin de «saciar su voracidad». Por este motivo, se aconseja a los pescadores que sigan el ejemplo de las sardinas y se atraquen a la aguaza, «dado que hay posibilidad de buena pesca» ${ }^{19}$ (DGLA, s. v. aguaza).

che al va dai avocats $c$ la cjamese al torne cence ['Quien va a los abogados con la camisa vuelve sin ella'] (Martinis, 2010: 123). Dicho sea de paso que, en la citada lengua friulana, la consideración para con los abogados podría resumirse en el siguiente refrán: Lari e avocat a son un non sôl ['Ladrón y abogado son un solo nombre'] (Martinis, 2010: 122).

16 Transcribimos la variante hallada en Castañón; en cuanto a la que nos presenta el DGLA, coloca el substantivo aguaza entre signos de exclamación.

17 «Cuando esas manchas son oscuras, en Gijón las llaman los marineros de Cimadevilla, agua pregona» (Castañón, 1962: 21). Por otra parte, el plancton de que está compuesta la aguaza en el mencionado Gijón se denomina pioyina; de hecho, el Vocabulario gijonés de Castañón, citado por Viña (2003: 95), especifica que «Cuando los pescadores gijoneses ven el plancton por fuera, en grandes cantidades, lo llaman mosquitón, cuando lo ven de cerca, en cantidades grandes, gota».

18 He aquí el sentido de atracar en la presente paremia: 'aproximarse' o 'arrimarse'.

19 Al decir de Saralegui (1917: 173, núm. 314), que registra el refrán en la variante Aguaza... ¡Atraca!, y lo localiza en Avilés, «Por eso[,] tras los peces que se atracan o aproximan a tales manchas, se atracan, también, los pescadores para hacer su agosto». 


\section{(III) Caséstite, caguéstite}

Mientras que Martino (2008: 58) y Viejo (2012: 251, núm. 1508) optan por esta variante, Castañón (1962: 59) prefiere ¿Casástete? Cagástete ${ }^{20}$. El sentido de la paremia es bien claro: «Contra el matrimonio» ${ }^{21}$ (Castañón, 1962: 59). En efecto, la maledicencia a propósito de este ritual de paso fundamental en nuestro devenir vital (al menos desde un punto de vista folklórico) trufa el refranero romance de otros refranes mínimos (compuestos por dos elementos) similares. Así, en portugués, Casados, apartados o Casados, separados (Machado, 20114: 139); en gallego, Casáronte: cazáronte $^{22}$ (Ferro, 1995: 381, núm. 6760); en catalán, Casat, caçat ${ }^{23}$ (Amades, 1982²: 1111; Parés, 2000: 230, núm. 160), Casat, penedit²4 (Amades, 19823: 1109; Parés, 2000: 230, núm. 163) o Casament, encegament ['ofuscación'] (Parés, 2000: 229, núm. 134); o, en italiano, aprovechando el juego de palabras para dar rienda suelta a la misoginia, Sposa, spesa ${ }^{25}$ ['Esposa, gasto'] (Lapucci,

\section{Cfr. la Introducción.}

21 Acompañan a esta breve glosa cuatro versos («Entre casau y cansau [/] hay tan poca diferencia, [/] que nada más los estrema [/] d' una $\mathrm{N}$ la presencia»), un cantar de casada («Yo caseme con un vieyu [/] y enterrélu 'na ceniza, [/] púnxeme a llorar por él [/] y hube arreventar de risa»), el equivalente "valenciano» Yá t'as casat, ya t'as cagat (sic) y una copla no asturiana («Te casaste, te enterraste. [/] ¿no te lo decía yo? [/] El que se casa se entierra, [/] como a mí me sucedió»), cuyo primer verso coincide con un refrán español (cfr. Martínez, 1995: 454, núm. 39.652). Por otro lado, Castañón (1981: 264) afirma: «El cancionero y refranero asturianos parecen no ser excesivamente partidarios del matrimonio, al menos según se desprende de algunas expresiones folklóricas».

22 Cfr., en español, Quien dice casado, dice cazado (Martínez, 1995: 453, núm. 39.600) o Te casaron, te cazaron (núm. 39.601).

\section{3 Ídem.}

24 Cfr., en español, Casarás, y te arrepentirás (Martínez, 1995: 453, núm. 39.627).

25 Según la glosa del autor, «la sposa è una spesa continua, per le cose domestiche, l'abbigliamento, la cura della persona e le varie necessità» ['la mujer es un gasto continuo, por las cosas domésticas, el vestuario, el cuidado de la persona y las varias necesidades']. 
2007: 1502, núm. 1925). En lo que respecta a refranes constituidos por tres elementos, a veces, la coma de las paremias de dos elementos se substituye por la conjunción copulativa, la cual puede unir dos participios, como en el caso del gallego Casado e arrepentido (Ferro, 1995: 377, núm. 6692), o del español Casado, y arrepentido ${ }^{26}$ (Martínez, 1995: 453, núm. 39.631); o bien dos verbos conjugados, como en el portugués Casareis e amansareis $^{27}$ (Machado, 2011': 140), o el gallego Casaraste e arrepentiraste (Ferro, 1995: 377, núm. 6693). En definitiva, todos los ejemplos coinciden en una visión negativa del matrimonio que, a título conclusivo, podríamos resumir con la siguiente paremia francesa: Il y a plus de mariés que de contents ${ }^{28}$ (Montreynaud et al., 1993: 44, núm. 842).

(IV) Febreru, febreraes ${ }^{29}$ ['Febrero, febreradas']

Refrán que, a pesar de su brevedad, hermana ambos elementos en una preciosa derivación $a h$ hoc. Se encuentra registrado en los refraneros de Martino (2008: 113 y 155), Viejo (2012: 53, núm. 126) y Sánchez y Cañedo (2012: 119, núm. 1580). La variante Febrero, febreraes aparece en el DGLA ${ }^{30}$ (s. v. febrerada) y en Castañón (1962: 164).

26 Cfr. nota 24

27 Cfr. el refrán catalán: Casaràs? T'amansiràs (Parés, 2000: 230, núm. 154).

28 El italiano, en este aspecto, apunta: Chi si marita [/] si condanna a vita (Lapucci, 2007: 898, núm. 952), o Se non hai guai [/] spòsati e li avrai ['Si no tienes problemas [/] cásate y los tendrás'] (1503, núm. 1941).

29 Téngase en cuenta que, de los 38 refranes presentados en este artículo, tres se refieren al mes de febrero: Febreru, febreraes; Eneru, como Febreru; y Febrerué jornaleru.

30 Para acceder a los refranes del DGLA en los que aparece febrero, cfr. Gargallo (2010: 182). 
Dentro del ciclo anual, los meses que se hallan más nutridamente representados en el calendario de refranes son los que marcan el tránsito entre el tiempo de invierno y el primaveral, a diferencia de otros meses del año, como octubre o noviembre, con un aporte menor de refranes. Febrero, marzo y abril son los meses con personalidad más acentuada en el calendario de refranes, con fama general de maldad (Gargallo y Torres, 2009: 144).

No debería, pues, sorprendernos que en febrero, mes que originariamente cerraba el año romano ${ }^{31}$, sean frecuentes los ramalazos de mal tiempo ${ }^{32}$, como bien apuntan Viejo (2012: 53, núm. 126) y Castañón (1962: 164), autor que, además, sitúa el refrán en Gijón y lo circunscribe al ámbito marinero.

Diferentes lenguas romances han creado un verbo ad hoc para describir el tiempo habitual en febrero, es decir, las febreraes de nuestro refrán. Se trata del asturiano febreriar (DGLA y Sánchez, 2008, s. v. febreriar), del gallego febreirear ${ }^{33}$, del catalán febrejar ${ }^{34}$,

31 Gargallo y Torres (2009: 144) apuntan que la significación etimológica de februarius, forma derivada de februus, 'que purifica, purificador', tiene que ver con la renovación del año.

32 La mala fama de este mes, a pesar de su brevedad, se encuentra profusamente representada en el refranero romance; a título ejemplificativo, citamos el portugués Fevereiro o mais curto mês e o menos cortês (Machado, 20114: 246); el gallego Febreiro curto, o peor de todos (Ferro, 1995: 294, núm. 5033); el francés Février, entre tous les mois, [/] Le plus court et le moins courtois (Montreynaud et al., 1993: 121, núm. 67); el italiano Febbraio, corto e amaro (Lapucci, 2007: 541, núm. 473); y, como conclusión, el friulano Fevrarut piês di dut ['Febrerillo[,] peor de todo'] (Martinis, 2010: 59). Para más resultados romances, cfr. en Correas y Gargallo (2003: 61) el apartado «El mes más corto y el más temible».

33 Cfr. Cando febreiro non febreirea, marzo marcea (Ferro, 1995: 293, núm. 5022) o Se febreiro non febreirea, marzo marcea (294, núm. 5044).

34 Cfr. Si el febrer no febreja, el març marceja (Parés, 2000: 94, núm. 1277) o Si el febrer no febreja, tot l'any bogeja (núm. 1279). 
del francés févrièrer ${ }^{35}$ o del italiano febbreggiare ${ }^{36}$. Aportamos, a continuación, una serie de refranes mínimos romances formados por dos elementos y que aluden, como la paremia asturiana, al mes de febrero. Así, en portugués, Fevereiro, chover o Fevereiro grãozeiro ['sembrador de grano'] (Machado, 20114: 246); en gallego, Febreiro, cabriteiro ['vendedor de cabritos'] (Ferro, 1995: 294, núm. 5035) o Febreiro, cebadeiro (núm. 5036); en español, Febrero, cebadero (Martínez, 1995: 116, núm. 10.432), que coincide con la anterior paremia gallega; o, en italiano, ... febbraio potatore... ['podador'] (Lapucci, 2007: 542, núm. 494).

Para cerrar este apartado, recurriremos a una retahíla de posibles refranes mínimos (entre los cuales uno con febrero), que, sin embargo, no acaban de serlo al presentarse siempre unidos: $X i-$ neru paxareru, febreru parexeru, marzu niarzu, abril güeveril, mayu paxarayu y en San Xuan volarán $n^{37}$ ['Enero pajarero (empiezan a verse los pájaros), febrero parejero (se emparejan en este mes), marzo niarzo (pues hacen el nial 'nido'), abril hueveril (ponen los huevos), en mayo pajarillo y en San Juan volarán (las crías)' $]^{38}$ (Viejo, 2012: 43, núm. 64).

35 Cfr. Si février ne «févrière» pas, [/] Tout mois de l'an peu ou prou le fera (Montreynaud et al., 1993: 121, núm. 74).

36 Cfr. Se febbraio non febbreggia, marzo campeggia (Schwamenthal y Straniero, 1991: 464, núm. 5071). Para más ejemplos romances, cfr. en Correas y Gargallo (2003: 62) el apartado «Entre febrero y marzo».

37 García (1976: 547) opta por la variante: Xineru paxareru, Febreru parexeru, Marzo niarzo, Abril güeveril, Mayo paxarayo y en San Xuan volarán.

38 La detallada traducción pertenece a la citada fuente, que, además, incluye el siguiente comentario: «Este refrán, referente al ciclo de cría de las aves, aparece con la misma estructura en múltiples variantes, situando en cada caso en un mes diferente el inicio o el fin del proceso». 
Refranes mínimos constituidos por tres elementos

Aunque, de los 34 refranes mínimos constituidos por tres elementos que nos ofrecen nuestras fuentes ${ }^{39}$, algunos muestren una clara hechura española ${ }^{40}$, preferimos pecar de prudentes e incluirlos en nuestro corpus (cfr. el Apéndice). De estas paremias, analizamos a continuación las formulaciones más recurrentes ${ }^{41}$.

(1) Quien + verbo[,] + verbo

Esta estructura se repite en tres ocasiones:

- Quien espera, desespera (Viejo, 2012: 363, núm. 2820). Así, en portugués, Quem espera desespera (Machado, 20114: 512); en gallego, O que espera, desespera (Ferro, 1995: 273, núm. 4561); en catalán, Qui espera es desespera (Parés, 2000: 190, núm. 5165); reservamos para el final dos refranes españoles con remate: Quien espera, desespera, si no alcanza lo que desea (Martínez, 1995: 252, núm. 22.969) y Quien espera desespera, y esperando se consuela (núm. 22.970).

- Quien guarda, faya42 ['Quien guarda, encuentra'] (Castañón, 1962: 251; Viejo, 2012: 364, núm. 2823). Dicho refrán, con el que principia el título del presente trabajo, aparece en la correspondencia de Jovellanos, concretamente en una epístola a Carlos González de Posada, fechada en Gijón el 14 de enero de 1801, en la que el autor alude al cuarto certamen público del Real Instituto Asturiano:

39 Recordemos, una vez más, que se trata de los refraneros de Castañón (1962), ampliado con dos apéndices (Castañón, 1963 y 1965), Martino (2008), Viejo (2012) y Sánchez y Cañedo (2012).

40 Cabe apuntar que todos pertenecen a Castañón (1962 y 1963).

41 No citamos las variantes de los refranes presentados, ya que pueden consultarse en el cuadro del Apéndice.

42 En el ámbito romance, compárese con las siguientes paremias: en portuguès, Quem guarda achalencontra/tem (Machado, 2011: 516); en gallego, Quen garda, atopa (Ferro, 1995: 66, núm. 211); en español, Quien guarda, halla (Martínez, 1995: 20, núm. 1.808); en catalán, Qui guarda, troba (Farnés, 1995: IV, 877, núm. G1062); o, en italiano, Chi risparmia ritrova (Lapucci, 2007: 1343, núm. 668). 
Habrá premio de dibujo, será usted quien le da, y nada tendrá que desembolsar. ¿Cómo es esto? Yo lo diré: quien guarda, faya. La prevención de estampas que envió Ceán el año pasado, y aun la de papel, era tan escogida y copiosa, que se reservó alguna parte para uso del Instituto. De ésta sacaremos para premiar este año, (...) (Jovellanos, 1986: 606).

- Quien tien, retien ['Quien tiene, retiene'] (Viejo, 2012: 366, núm. 2863).

Finalmente, cabe citar el refrán Perde quen ten (Sánchez y Cañedo, 2012: 167, núm. 3473), que altera el orden analizado aquí, *Quen ten perde, para subrayar, anticipándolo al inicio, el aciago destino de quen ten: perder.

(2) Conjunción + verbo[,] + verbo

Complementando el apartado anterior, citamos a continuación un par de paremias que sustituyen el anterior pronombre quien por una conjunción (como y onde, respectivamente):

- Como semaredes recoyeredes ['Como sembraréis recogeréis'] (Sánchez y Cañedo, 2012: 81, núm. 13); idéntica formulación en catalán, Com sembrareu collireu (Parés, 2000: 373, núm. 1541). Con segunda persona del singular, en vez de plural, en portugués, Como semeares assim colherás (Machado, 20114: 159); en gallego, Tal como sementes, collerás (Ferro, 1995: 532, núm. 9842); en español, Como sembrares cogerás (Martínez, 1995: 665, núm. 58.119); o, en italiano, Come seminerai, così raccoglierai (Schwamenthal y Straniero, 1991: 175, núm. 1904).

- Onde pago, cago ['Donde pago, cago'] (Castañón, 1962: 225; Martino, 2008: 81; Viejo, 2012: 352, núm. 2666; Sánchez y Cañedo, 2012: 167, núm. 3465); coincidente con el gallego Onde pago, cago (Ferro, 1995: 271, núm. 4522). Asimismo, resulta curioso constatar la presencia del escatológico verbo cagar en tres refranes mínimos de nuestro corpus; además del presente y del ya analizado ¿Casástete? Cagástete, también hallamos la paremia Formal morreo cagando. 
(3) Substantivo sujeto + verbo transitivo + substantivo objeto directo

Este apartado se caracteriza por la preeminencia del primer substantivo, el cual, a través del verbo central, se impone sobre el segundo substantivo. Así:

- Condición mata derechu (Martino, 2008: 188; Viejo, 2012: 255, núm. 1553; Sánchez y Cañedo, 2012: 163, núm. 3274).

- Crianza quita labranza (Castañón, 1963: 255).

- Tripes lleven pies (Castañón, 1962: 295; Martino, 2008: 122; Viejo, 2012: 379, núm. 3024; Sánchez y Cañedo, 2012: 113, núm. 1339); refrán que, con un remate, se encuentra en el Quijote (II, Cap. 34): Tripas llevan pies, que no pies a tripas ${ }^{43}$. Aprovechando la traducción asturiana de la obra maestra cervantina, comprobamos que la versión de Pablo Suárez coincide, en su primera parte, con el refrán asturiano: Tripes lleven pies, que non pies a tripes (Cervantes, 2015: 568). Además, el traductor, en nota a pie de página ${ }^{44}$, remite a «RTA 122-1-7» $»^{45}$, es decir, al séptimo refrán (7) de la primera columna (1) de la página 122 de nuestro bien conocido, y ya citado, Refraneru temáticu asturianu (RTA), obra de Xandru Martino (2008), donde, efectivamente, hallamos la paremia Tripes lleven pies.

- Dineru llama dineru (Castañón, 1962: 101). Este último ejemplo se diferencia del resto en la repetición del mismo substantivo, circunstancia que, sin embargo, no altera la primacía del primero sobre el segundo. En este sentido, Castañon (1962: 101102), después de apuntar que «Se suele agregar: pero lo mucho a lo poco» ${ }^{46}$, transcribe la siguiente anécdota:

43 Para más detalles sobre este refrán quijotesco, así como sobre sus equivalentes romances, cfr. Fontana (2014: 391-392).

44 Se trata de la nota 2856.

$45 \mathrm{El}$ hecho de que, normalmente, Pablo Suárez indique con una nota a pie de página la procedencia bibliográfica de los refranes asturianos utilizados constituye una rara avis (a nivel panrománico) de incalculable valor para los paremiólogos.

46 Así, en español, Dinero llama dinero; pero es lo más a lo menos (Martínez, 1995: 204, núm. 18.550); o, en tres paremias similares: Allá va la plata donde haya más plata 
Un paisanín fue a un Banco. Allí se arrimó a un mostrador y sacó una moneda, pues basándose en lo de dineru llama dineru pensaba que pudiera venir hacia él algo de lo mucho que en el Banco había; entonces, se le escapó su moneda de la mano y rodó hacia el interior del Banco. Dijo el hombre: «Sí, dineru llama dineru, pero lo mucho a lo poco».

Dicha formulación se halla también en portugués: Dinheiro chama dinheiro (Machado, 20114: 195); en gallego: Diñeiro gaña diñeiro (Ferro, 1995: 242, núm. 3935); o en italiano: Soldi chiamano soldi (Lapucci, 2007: 1475, núm. 1513).

(4) Verbo con pronombre $+X+$ Verbo con pronombre

Este apartado ofrece tres ejemplos que tienen en común la relación de igualdad o/y continuidad que se establece entre dos verbos, acompañados ambos de un pronombre enclítico, a través de una preposición (con) o de una conjunción (pues y y).

- Axuntóse con topóse ['Se juntó con se topó'] (Sánchez y Cañedo, 2012: 132, núm. 2065).

- ¿Díxolo? Pos faralo ['¿Lo dijo? Pues lo hará'] (Castañón, 1962: 105); en un apunte correspondiente al martes 28 de julio de 1795, Jovellanos anota en su diario:

Malísima posada, sucia hasta la inmundicia; estamos a cuatro leguas de Gijón y, sin embargo, se trata de dormir en La Pola y mañana hacer otra jornada, a comer en la venta de Puga y dormir en casa; es decir, tomar más sol, oler más malas posadas y sufrir pulgas, alquiladores y demonios colorados. ¡He aquí lo que se gana en seguir el capricho de las mujeres! Y ¿cuál es su objeto? Ninguno, sino llevar la contraria. ¿Díxolo? Pos farálo ${ }^{47}$ (Jovellanos, 1992: 272-273).

(núm. 18.546); Siempre van las monedas donde hay más compañeras (núm. 18.548); o Dinero, ¿adónde vas? —Adonde hay más (núm. 18.547).

$47 \mathrm{El}$ editor acompaña nuestra paremia con la siguiente traducción en nota a pie de página (nota 232): «¿Lo dijo? Pues lo hará». 
- Ayúdame y ayudaréte ['Ayúdame y te ayudaré'] (Viejo, 2012: 242, núm. 1402); este refrán se distingue de los dos precedentes en la variación del pronombre enclítico que marca la alternancia de beneficiario y benefactor; es decir, el hecho de que ahora tú «me» ayudes redundará en que mañana yo «te» ayudaré a ti. Asimismo, en portugués, Ajuda-me que eu te ajudarei (Machado, 2011: 71).

(5) $\mathrm{La}+$ substantivo femenino + verbo intransitivo

Únicamente cuatro refranes de nuestro corpus incluyen el artículo determinado, siempre en singular. En un caso, se trata del artículo masculino (El postreiru cancel·leiru), mientras que, en los otros tres, del femenino. En dos de estos últimos ${ }^{48}$, observamos una estructura idéntica formada por el citado artículo determinado femenino singular, seguido por el correspondiente substantivo, así como por un verbo intransitivo:

- La burruca ruca ['La borrica (también) zampa'] (Castañón, 1962: 172).

- La trampa rescampla ['La trampa trasluce'] (Viejo, 2012: 323, núm. 2326).

(6) Construcciones copulativas

Acabamos este breve repaso a las estructuras más recurrentes en los refranes mínimos asturianos constituidos por tres elementos con un cajón de sastre que contiene diferentes tipos de construcción copulativa. En primer lugar, citamos las paremias con verbo explícito:

- «Avilés, hábil es» (Castañón, 1962: 47); hábil calambur de clara hechura española, en el que acaso avilés no sea topónimo sino gentilicio, y, por tanto, pueda aludir al habitante de Ávila.

$48 \mathrm{El}$ tercer caso, es decir, el que no se adapta a la estructura descrita, corresponde a la paremia La pez, darála. 
- Febreru é jornaleru ['Febrero es jornalero'] (Viejo, 2012: 51, núm. 116); también, en catalán, El febrer ja és jornaler ${ }^{49}$ (Parés, 2000: 90, núm. 1155).

- Caún ye caún ['Cada uno es cada uno'] (Viejo, 2012: 251, núm. 1515); construcción tautológica que nos recuerda el refrán portugués Cada um é um (Machado, 2011": 130).

Anotamos a continuación los refranes en los que se ha elidido el verbo ser:

- Cielo escamudo, vendovaludo ['Cielo empedrado, ventoso'] (Castañón, 1962: 62); en portugués, el viento también puede convertirse en lluvia: Céu pedrento, chuva ou vento (Machado, 2011". 145).

- Home peludu, fortalexudu ['Hombre peludo, con fortaleza'] (Sánchez y Cañedo, 2012: 128, núm. 1933); en gallego, Home peludo, home valente e forzudo (Ferro, 1995: 455, núm. 8221); y, en español, Hombre muy velludo, hombre forzudo (Martínez, 1995: 721, núm. 62.740).

- El postreiru cancel.leiru ['El último, cancelero'] (Viejo, 2012: 285, núm. 1890); el sentido de este refrán se explica con equivalentes como el portugués $O$ último que vem que feche a porta (Machado, 20114: 424), el italiano L'ultimo chiuda la porta (Schwamenthal y Straniero, 1991: 519, núm. 5664), o el friulano Cui ch'al jentre ultin [/] ch'al sieri la puarte ['Quien entra último [/] que cierre la puerta'] (Ostermann, 1995: 189).

- Gochu, pero persanu ['Cerdo, pero sanísimo'] (Martino, 2008: 129; Sánchez y Cañedo, 2012: 110, núm. 1219; Viejo, 2012: 402, núm. 3318).

- Eneru, como Febreru (Castañón, 1963: 264).

- En Campiellos, caractiellos ['En Campiellos, escuchimizados'] (Castañón, 1963: 264); el autor, que sitúa Campiellos en Sobrescobio, traduce el adjetivo caractiellos por partida doble: «flacos,

49 Con la glosa: «El dia ja s'allarga més, i per tant ja es pot treballar més hores». Este refrán también aparece en el DCVB (s. v.febrer), en la variante Al febrer, ja és jornaler, con un comentario similar: «Vol dir ['Quiere decir'] que el dia ja s'ha allargat considerablement». 
desmedrados». Compárese este típico ejemplo de maledicencia popular con otro referido a la supuesta tacañería propia de los habitantes de la capital del citado concejo de Sobrescobio: Rusecu, puñu secu ['Rioseco, puño seco'] (Castañón, 1963: 275); paremia que no hemos incluido en este apartado pues todo apunta a que el verbo elidido sería tener.

\section{Reflexión final}

A título conclusivo, citamos cuatro refranes mínimos del Quijote, compuestos todos ellos por tres elementos, y que acompañamos, intencionadamente, con su correspondiente traducción asturiana (según Cervantes, 2015):

- Cortesías engendran cortesías (II, Cap. 61) > Cortesíes enxendren cortesies (Cervantes, 2015: 715);

- Dádivas quebrantan peñas (II, Cap. 35) > Dádives frañen peñes (Cervantes, 2015: 575);

- Paciencia y barajar (II, Cap. 23 y 24) > Paciencia y embaraxar ${ }^{50}$ (Cervantes, 2015: 504 y 509);

- Peor es meneallo (I, Cap. 20) > Peor ye ximelgalo (Cervantes, 2015: 127).

En todos los ejemplos propuestos, la versión asturiana ad litteram elegida por Pablo Suárez convierte dichas soluciones en impecables refranes mínimos asturianos, compuestos por tres elementos, que, sin embargo, carecen de tradición paremiológica ${ }^{51}$ (es decir, resulta imposible localizarlos en ninguno de los repertorios consultados).

Sirva este experimento para poner de relieve que, en el caso de los refranes, su fortuna depende de algo tan simple, $y$, a la vez, tan impredecible, como el uso, o desuso, que de ellos haga el pueblo. Así, un refrán antaño muy habitual en el litoral de As-

50 La versión de la página 504 se acompaña de la siguiente nota a pie de página: «Metáfora del xuegu les cartes» (nota 2580).

51 No en balde, Pablo Suárez no acompaña dichas versiones parémicas de ninguna nota a pie de página con la correspondiente fuente bibliográfica, como sí que acostumbra a hacer cuando se trata de paremias recopiladas en algún refranero asturiano. 
turias, como Aguaza ;Atraca!, hoy en día, con la progresiva desaparición de los marineros, y del acervo de su ancestral cultura, puede acabar convirtiéndose en la fosilizada muestra etnográfica de otros tiempos. Por otro lado, la creación o el uso de un refrán para ciertas situaciones, nuevas o no, para los que algunas paremias han perdido su validez o ya no se sienten como propias (en muchos casos por culpa de un léxico o de una costumbre que el hablante considera extemporáneos ${ }^{52}$ ) puede enriquecer el refranero con nuevas aportaciones ${ }^{53}$.

El corpus que hemos presentado (38 refranes mínimos en total: cuatro formados por dos elementos, y 34, por tres) solo pretende rendir un humilde homenaje a Asturias, «región privilegiada en cuanto a su acervo refranero, pues[,] dentro de sus tradiciones populares, los refranes ocupan un área importante, tanto por su cantidad como por su variedad $»^{54}$ (Castañon, 1981: 257); en razón de nuestra esperanza de que, en un futuro, paremiólogos, lingüistas o etnógrafos (doctores habet Ecclesia) se encarguen de ampliar, $\mathrm{y}$, por tanto, de analizar más pormenorizadamente, la breve muestra de refranes aquí mostrada.

52 Pensemos, por ejemplo, en el refrán La cirigüeña ['celedonia'] de to los males ye dueña (Castañón, 1962: 174). El DGLA (s. v. cerigüeña) reporta la variante La cirigüeña de tolos males ya dueña e ilustra la entrada con una fotografía de esta planta acompañada por el siguiente pie: «La cerigüeña... que de tolos males ye dueña». Hoy en día, deben de ser bien pocos los que conozcan, y menos aún los que empleen médicamente, dicha planta.

$53 \mathrm{Si}$ el refranero asturiano contiene una paremia como Dádiva retrasada - val pouco o nada (Fernández, 1984: 183; dentro del apartado Tacañería), ¿quién nos asegura que la propuesta de traducción parémica quijotesca Dádives frañen peñes (Cervantes, 2015: 575), que en la actualidad no ha perdido ni un ápice de valor, no acabe penetrando en el uso cotidiano de la lengua?

54 «Pese a la casi exhaustiva recopilación que hemos realizado en los más diversos lugares, todavía aparece algún refrán inédito cuando consultamos a nuevas personas en una braña o en pueblos apartados» (Castañón, 1968: 257). 


\section{Apéndice}

En este apéndice, ofrecemos dos cuadros: el primero, con los cuatro refranes mínimos compuestos por dos elementos; y el segundo, que comprende los 34 refranes mínimos de tres elementos. Las paremias se presentan en orden alfabético y se acompañan sistemáticamente de traducción (en la columna de la derecha) siempre que ésta no coincida con el refrán presentado. Además, en nota a pie de página se incluyen las glosas, comentarios o notas al pie halladas en las fuentes bibliográficas consultadas. Finalmente, debajo de la traducción, se consignan, si es el caso, las posibles variantes de la paremia principal.

\begin{tabular}{|c|c|c|}
\hline Núm. & $\begin{array}{c}\text { Refrán mínimo } \\
\text { (dos elementos) }\end{array}$ & Traducción y variantes \\
\hline I & $\begin{array}{c}\text { Abogáu, afogáu } \\
\text { (DGLA, s. v. abogáu y } \\
\text { afogáu; Martino, 2008: 61 y } \\
\text { 193; Viejo, 2012: 388, núm. } \\
\text { 3135; Sánchez y Cañedo, } \\
\text { 2012: 100, núm. 783) }\end{array}$ & [‘Abogado, ahogado’] \\
\hline II & $\begin{array}{c}\text { «Aguaza», ;atraca!55 } \\
\text { (Castañón, 1962: } 21)\end{array}$ & $\begin{array}{c}\text { (DGLA, s. v. aguaza) } \\
\text { (DGua! jatraca! }\end{array}$ \\
\hline
\end{tabular}

55 “Aguaza: manchas verdosas en el mar, en las cuales hay abundancia de sardina. Cuando esas manchas son oscuras, en Gijón las llaman los marineros de Cimadevilla, agua pregona; están compuestas dichas aguas de plankton, en vocabulario gijónés pioyina y gota". 


\begin{tabular}{|c|c|c|}
\hline III & $\begin{array}{l}\quad \text { Caséstite, caguéstite } \\
\text { (Martino, 2008: 58; Viejo, } \\
\text { 2012: 251, núm. 1508) }\end{array}$ & $\begin{array}{l}\text { [‘Te casaste, te cagaste’] } \\
\text { ¿Casástete? Cagástete } \\
\text { (Castañón, 1962: 59) } \\
\text { «—_Casastete? } \\
\text { Cagastete» }{ }^{57} \\
\text { (Pérez, 1963: 125, núm. 28) }\end{array}$ \\
\hline IV & $\begin{array}{l}\quad \text { Febreru, febreraes }^{58} \\
\text { (Martino, 2008: } 113 \text { y 155; } \text { Viejo, 2012: 53, núm. 126; } \\
\text { Sánchez y Cañedo, 2012: } \\
\text { 119, núm. 1580) }\end{array}$ & $\begin{array}{c}\text { ['Febrero, febreradas'] } \\
\text { Febrero, febreraes }{ }^{59} \\
\text { (Castañón, 1962: 164; } \\
\text { DGLA, s. v. febrerada) }\end{array}$ \\
\hline
\end{tabular}

\begin{tabular}{|c|c|c|}
\hline Núm. & $\begin{array}{c}\text { Refrán mínimo } \\
\text { (tres elementos) }\end{array}$ & Traducción y variantes \\
\hline 1 & $\begin{array}{c}\text { Arrepentíos quier Dios } \\
\text { (DGLA, s. v. arrepentise; } \\
\text { Viejo, 2012: 241, núm. 1390) }\end{array}$ & $\begin{array}{c}\text { ['Arrepentidos quiere } \\
\text { Dios'] }\end{array}$ \\
\hline 2 & $\begin{array}{c}\text { "Avilés, hábil es»60 } \\
\text { (Castañón, 1962: 47) }\end{array}$ & \\
\hline
\end{tabular}

56 “Contra el matrimonio". Cfr. en la nota 21 la información adicional ofrecida por el autor.

57 “De «Arte y Letras», núm. 38, dedicado a Asturias. Del ms. del Dr. G. Oliveros. Lo incluye también CASTAÑón, Refranero..., p. 59".

58 Viejo transcribe el comentario de Castañón: “En febrero nunca faltan los ramalazos de mal tiempo". Cfr. la siguiente nota.

59 “Marinero. Gijón. En Febrero nunca faltan los ramalazos de mal tiempo" (Castañón, 1962: 164).

60 “Lo pone G. I. en su «Refranero del mar» pero este «Avilés» debe referirse al natural de Avila y no a nuestro puerto. (Vergara lo pone como de Avila)". 


\begin{tabular}{|c|c|c|}
\hline 3 & $\begin{array}{c}\text { Axuntóse con topóse }{ }^{61} \\
\text { (DGLA, s. v. axuntar; } \\
\text { Sánchez y Cañedo, 2012: } \\
\text { 132, núm. 2065) }\end{array}$ & ['Se juntó con se topó'] \\
\hline 4 & $\begin{array}{l}\text { Ayúdame y ayudaréte } e^{62} \\
\text { (DGLA, s. v. axudar; Viejo, } \\
\text { 2012: 242, núm. 1402) }\end{array}$ & $\begin{array}{c}\text { ['Ayúdame y te } \\
\text { ayudaré'] } \\
\text { Ayúdate y ayudaréte } \\
\text { (Sánchez y Cañedo, } \\
\text { 2012: 159, núm. 3149) }\end{array}$ \\
\hline 5 & $\begin{array}{l}\text { Birolete, tejero vete } \\
\text { (Castañón, 1963: 253) }\end{array}$ & ['Virolete, tejero vete'] \\
\hline 6 & $\begin{array}{c}\text { Caún ye caún }{ }^{64} \\
\text { (Viejo, 2012: 251, núm. } \\
\text { 1515) }\end{array}$ & $\begin{array}{l}\text { [‘Cada uno es cada } \\
\text { uno'] } \\
\text { Cadún ya cadún } \\
\text { (DGLA, s. v. caún) }\end{array}$ \\
\hline
\end{tabular}

61 “Tal para cual” (DGLA, s. v. axuntar).

62 Viejo relaciona esta paremia con Agabítame y agabitaréte ['Ayúdame y te ayudaré'], trabaya y mantendréte.

63 Según glosa del autor: "Que cuando aparece esta planta es el tiempo de partir los tejeros del oriente de Asturias". Tanto el DGLA (s. v. virolete) como Sánchez (2008, s. v. virolete) la definen así: "Planta de flores azules, típica de lugares altos y húmedos".

64 Viejo cita tres paremias que completan el refrán inicial con un remate: Caún ye caún y ca dos una piragua; Caún ye caún y seis media docena; y Caún ye caún y tien les sos cadaúnaes. En esta última paremia, el DGLA (s. v. caún) nos ofrece una variante con caunaes en vez de cadaúnaes, y añade la siguiente glosa: "Cada uno es muy suyo".

65 “Cada uno es como es". 


\begin{tabular}{|c|c|c|}
\hline 7 & $\begin{array}{l}\text { Cielo escamudo, } \\
\text { vendovaludo6 } \\
\text { (Castañón, 1962: 62; } \\
\text { DGLA, s. v. escamudar y } \\
\text { vendovaludu) }\end{array}$ & $\begin{array}{c}\text { ['Cielo empedrado, } \\
\text { ventoso'] }\end{array}$ \\
\hline 8 & $\begin{array}{l}\text { Como semaredes recoyeredes } \\
\text { (Sánchez y Cañedo, 2012: } \\
\text { 81, núm. 13) }\end{array}$ & $\begin{array}{l}\text { ['Como sembraréis } \\
\text { recogeréis'] }\end{array}$ \\
\hline 9 & $\begin{array}{l}\text { Condición mata derechu } \\
\text { (DGLA, s. v. condición y } \\
\text { derechu; Martino, 2008: } \\
\text { 188; Viejo, 2012: 255, núm. } \\
\text { 1553; Sánchez y Cañedo, } \\
\text { 2012: 163, núm. 3274) }\end{array}$ & $\begin{array}{c}\text { ['Condición mata } \\
\text { derecho'] }\end{array}$ \\
\hline 10 & $\begin{array}{l}\text { Crianza quita labranza } \\
\text { (Castañón, 1963: 255) }\end{array}$ & \\
\hline 11 & $\begin{array}{l}\quad \text { Dineru llama dineru } \\
\text { (Castañón, 1962: 101; } \\
\text { DGLA, s. v. dineru) }\end{array}$ & ['Dinero llama dinero'] \\
\hline
\end{tabular}

66 "Marinero. Santander: Raboti oscuru, ábrigu seguru. (Nubes con forma de rabo presagian viento)" (Castañón, 1962: 62).

67 “Pascual Pastor López, «Memoria geognóstico-agrícola sobre la provincia de Asturias...», M., 1853, p. 56: «Según lo expuesto, convienen pues al suelo de Asturias, como sistema de siembra, los productos que estén en relación con su clima agrícola, caracterizado por el castaño, manzano y roble; y con la industria ganadera, en creciente decadencia hoy, desechando la absurda máxima: crianza quita labranza, pues la experiencia la desacredita...»".

68 "Se suele agregar: pero lo mucho a lo poco". Castañón, además, explica la anécdota de un paisanín que fue a un banco y que no reproducimos por haberla citado anteriormente (cfr. el punto 3 en "Refranes mínimos constituidos por tres elementos"). 


\begin{tabular}{|c|c|c|}
\hline 12 & $\begin{array}{l}\text { ¿Díxolo? Pos faralo69 } \\
\text { (Castañón, 1962: 105) }\end{array}$ & $\begin{array}{l}\text { ['¿Lo dijo? Pues lo hará'] } \\
\text { «—Dï̈olo? Pos faralo» } \\
\text { (Pérez, 1963: 126, núm. } \\
\text { 37) }\end{array}$ \\
\hline 13 & $\begin{array}{c}\text { El postreiru cancel.leiru }{ }^{71} \\
\text { (Viejo, 2012: 285, núm. } \\
1890)\end{array}$ & $\begin{array}{c}\text { [‘El último, cancelero'] } \\
\text { El postreiru cancelleiru }{ }^{72} \\
\text { (DGLA, s. v. cancelleru y } \\
\text { postreru) }\end{array}$ \\
\hline 14 & $\begin{array}{l}\text { En Campiellos, caractiellos } \\
\text { (Castañón, 1963: 264) }\end{array}$ & $\begin{array}{l}\text { ['En Campiellos, } \\
\text { escuchimizados'] }\end{array}$ \\
\hline 15 & $\begin{array}{l}\text { Eneru, como Febreru } \\
\text { (Castañón, 1963: 264) }\end{array}$ & ['Enero, como Febrero'] \\
\hline
\end{tabular}

69 “Jovellanos, Diarios, (IDEA), II, 144; frase, esta vez para demostrar la caprichosa voluntad de las mujeres".

70 “(Jovellanos: Diarios, Oviedo, 1953, t. II, p. 144; y lo repite Castañón: Refranero..., p. 105.)".

71 "El último debe cerrar la puerta". El autor lo marca como "asturiano occidental".

72 “El último debe de cerrar" (s. v. cancelleru) y “El último debe cerrar la puerta" (s. v. postreru).

73 "Campiellos, (Sobrescobio). Es decir, flacos, desmedrados".

74 “Tan malo uno como otro. Referido también a las personas”. 


\begin{tabular}{|c|c|c|}
\hline 16 & 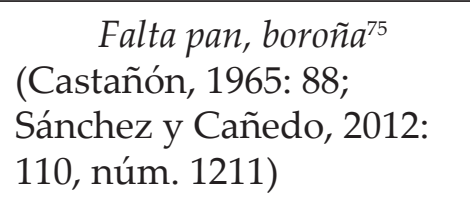 & $\begin{array}{l}\text { [’Falta pan, borona'] } \\
\text { Halta pan, boroña } a^{76} \\
\text { (Álvarez, 1963: 129) }\end{array}$ \\
\hline 17 & $\begin{array}{c}\text { Febrerué jornaleru } \\
\text { (Viejo, 2012: 51, núm. 116) }\end{array}$ & $\begin{array}{c}\text { [‘Febrero es jornalero'] } \\
\text { Febreru e jornaleru } \\
\text { (DGLA, s. v. xornaleru) } \\
\text { Febreru ye xornaleru } \\
\text { (Sánchez y Cañedo, } \\
\text { 2012: 150, núm. 2753) }\end{array}$ \\
\hline 18 & $\begin{array}{c}\text { Formal morreo cagando } \\
\text { (Sánchez y Cañedo, 2012: } \\
\text { 143, núm. 2495) }\end{array}$ & $\begin{array}{l}\text { ['Formal murió } \\
\text { cagando'] }\end{array}$ \\
\hline 19 & $\begin{array}{l}\quad \text { Gochu, pero persanu } \\
\text { (Martino, 2008: 129; Viejo, } \\
\text { 2012: 402, núm. 3318; } \\
\text { Sánchez y Cañedo, 2012: } \\
\text { 110, núm. 1219) }\end{array}$ & ['Cerdo, pero sanísimo'] \\
\hline
\end{tabular}

75 El DGLA nos ofrece una versión compuesta por cinco elementos (que citamos a pie de página pues no entraría en la categoría de refrán mínimo): A falta de pan, boroña; que se completa con la siguiente glosa: "Hay que contentarse con lo que se tiene aunque sea poco". El valor de la borona, puesto en entredicho por nuestra paremia, se resarce gracias al refrán $N u^{\prime}$ hay suerte bona - cumu salir cun borona (Fernández, 1984: 170).

76 Localizado por el autor en Arenas de Cabrales.

77 "Ya deben iniciarse algunas tareas del campo".

78 Superlativo formado a partir de un prefijo (en este caso, la preposición per), que nos recuerda, en el ritual ortodoxo rumano, el uso de ciertos adjetivos prefijados con el adverbio prea ['mucho, demasiado'], como, por ejemplo, preasfânt ['muy santo, santísimo']. 


\begin{tabular}{|c|c|c|}
\hline 20 & $\begin{array}{l}\text { Gochu, pergochu }{ }^{[79]} \text { dafechu } \\
\text { (DGLA, s. v. dafechu; } \\
\text { Martino, 2008: 129; } \\
\text { Sánchez y Cañedo, 2012: } \\
\text { 94, núm. 550) }\end{array}$ & $\begin{array}{c}\text { ['Cerdo, completamente } \\
\text { cerdísimo'] }\end{array}$ \\
\hline 21 & $\begin{array}{l}\text { Home peludu, fortalexudu } \\
\text { (Sánchez y Cañedo, 2012: } \\
\text { 128, núm. 1933) }\end{array}$ & $\begin{array}{c}\text { ['Hombre peludo, con } \\
\text { fortaleza'] } \\
\text { Hombre peludu, } \\
\text { fortalexudu } \\
\text { (DGLA, s. v. fortalexudu) }\end{array}$ \\
\hline 22 & $\begin{array}{l}\text { La burruca ruca } \\
\text { (Castañón, 1962: 172; } \\
\text { DGLA, s. v. burra) }\end{array}$ & $\begin{array}{c}\text { ['La borrica (también) } \\
\text { zampa'] }\end{array}$ \\
\hline 23 & $\begin{array}{l}\qquad \text { La pez, darála } \\
\text { (Sánchez y Cañedo, 2012: } \\
\text { 135, núm. 2197) }\end{array}$ & $\begin{array}{c}\text { [‘La pez, la dará'] } \\
\text { La pez, daralala } \\
\text { (Castañón, 1962: 181) }\end{array}$ \\
\hline
\end{tabular}

79 Ídem.

80 El DGLA (s. v. dafechu) incluye dos refranes mínimos más que, puesto que no somos capaces de registrar en ninguna otra fuente, no incluimos en nuestro corpus; se trata de Tochu, pertochu dafechu (DGLA, s. v. dafechu) y Desmanganióse dafechu (DGLA, s. v. dafechu y desmanganiar). Sirvan, pues, como ejemplo de las copiosas posibilidades de trabajo, en el ámbito de los refranes mínimos asturianos, que este artículo no pretende sino alentar.

81 “La mala inclinación, tarde o temprano se pondrá de manifiesto”. 


\begin{tabular}{|c|c|c|}
\hline 24 & $\begin{array}{c}\text { La trampa rescampla } \\
\text { (DGLA, s. v. rescamplar y } \\
\text { trampa; Viejo, 2012: 323, } \\
\text { núm. 2326) }\end{array}$ & ['La trampa trasluce'] \\
\hline 25 & $\begin{array}{l}\text { Muncha llonganiza empapiza } \\
\text { (Castañón, 1962: 209; } \\
\text { DGLA, s. v. empapizar y } \\
\text { llonganiza; Martino, 2008: } \\
\text { 31; Viejo, 2012: 337, núm. } \\
\text { 2488) }\end{array}$ & $\begin{array}{c}\text { [‘Mucha longaniza se } \\
\text { atraganta'] } \\
\text { Muncha llonganiza } \\
\text { empapiella } \\
\text { (Sánchez y Cañedo, } \\
\text { 2012: 111, núm. 1266) }\end{array}$ \\
\hline 26 & $\begin{array}{l}\text { Naide ñaz deprendíu³ } \\
\text { (Martino, 2008: 77; Viejo, } \\
\text { 2012: 339, núm. 2517; } \\
\text { Sánchez y Cañedo, 2012: } \\
\text { 179, núm. 3924) }\end{array}$ & $\begin{array}{c}\text { [‘Nadie nace } \\
\text { aprendido'] } \\
\text { Naide nace depreso } \\
\text { (Castañón, 1962: 211) } \\
\text { Nengunu ñaz aprendíu } \\
\text { (DGLA, s. v. aprendíu) } \\
\text { Naide nació deprendíu }{ }^{85} \\
\text { (Castañón, 1962: 211) } \\
\text { Naide nazú aprendíu } \\
\text { (Viejo, 2012: 339, núm. } \\
\text { 2517) }\end{array}$ \\
\hline
\end{tabular}

82 Viejo relaciona esta paremia con Las trampas discurren mantes (“El que comete una trampa se descubre", según la interpretación del DGLA, s. v. trampa); por su parte, el DGLA apunta que la paremia "se dice en los juegos de niños".

83 Pablo Suárez traduce con Naide naz aprendíu (Cervantes, 2015: 563), en este caso, sin remisión paremiográfica a pie de página, el refrán del Quijote (II, Cap. 33) Nadie nace enseñado.

84 "Occ".

85 "Aprendido, amaestrado". 


\begin{tabular}{|c|c|c|}
\hline 27 & $\begin{array}{l}\text { Ofrecer non emprobez } \\
\text { (Castañón, 1962: 223; } \\
\text { DGLA, s. v. emprobecer) }\end{array}$ & $\begin{array}{c}\text { [‘Ofrecer no } \\
\text { empobrece’] } \\
\text { Ofrecer nun aprobez } \\
\text { (Martino, 2008: 70) } \\
\text { Ofrecer nun emprobez } \\
\text { (Martino, 2008: 179) } \\
\text { Ufiertar nun aprobez } \\
\text { (Martino, 2008: 70 y 180; } \\
\text { Sánchez y Cañedo, 2012: } \\
\text { 168, núm. 3498) }\end{array}$ \\
\hline 28 & $\begin{array}{l}\quad \text { Perde quen ten } \\
\text { (Sánchez y Cañedo, 2012: } \\
\text { 167, núm. 3473) }\end{array}$ & ['Pierde quien tiene'] \\
\hline 29 & $\begin{array}{l}\quad \text { Onde pago, cago } \\
\text { (Castañón, 1962: 225; } \\
\text { Martino, 2008: 81; Viejo, } \\
\text { 2012: 352, núm. 2666; } \\
\text { Sánchez y Cañedo, 2012: } \\
\text { 167, núm. 3465) }\end{array}$ & $\begin{array}{c}\text { [‘Donde pago, cago'] } \\
\text { Onde pago cago } \\
\text { (DGLA, s. v. pagar) }\end{array}$ \\
\hline 30 & $\begin{array}{c}\text { Quien espera, desespera } \\
\text { (Viejo, 2012: 363, núm. } \\
\text { 2820) }\end{array}$ & $\begin{array}{l}\text { Quien aspera desespera } \\
\text { (DGLA, s. v. esperar) }\end{array}$ \\
\hline
\end{tabular}

86 Según la glosa de Castañón: “Lo dicen los que tienen arrendado algo, cuando el propietario les llama la atención porque estropean la hacienda". 


\begin{tabular}{|c|c|c|}
\hline 31 & $\begin{array}{l}\quad \text { Quien guarda, faya }{ }^{87} \\
\text { (Castañón, 1962: 251; 1981: } \\
\text { 266; Viejo, 2012: 364, núm. } \\
\text { 2823) }\end{array}$ & $\begin{array}{c}\text { ['Quien guarda, } \\
\text { encuentra'] } \\
\text { Quien guarda faya } \\
\text { (DGLA, s. v. afayar) } \\
\text { Quien guarda, afaya } \\
\text { (Martino, 2008: 86) } \\
\text { Quien guarda afaya } \\
\text { (Sánchez y Cañedo, } \\
\text { 2012: 167, núm. 3480) }\end{array}$ \\
\hline 32 & $\begin{array}{c}\text { Quien tien, retién } \\
\text { (Viejo, 2012: 366, núm. } \\
\text { 2863) }\end{array}$ & $\begin{array}{c}\text { [‘Quien tiene, retiene'] } \\
\text { Quien tien retién } \\
\text { (DGLA, s. v. retener) }\end{array}$ \\
\hline 33 & $\begin{array}{l}\text { Rusecu, puñu secu }{ }^{89} \\
\text { (Castañón, 1963: 275) }\end{array}$ & ['Rioseco, puño seco'] \\
\hline 34 & $\begin{array}{l}\quad \text { Tripes lleven pies } \\
\text { (Castañón, 1962: 295; } \\
\text { Martino, 2008: 122; Viejo, } \\
\text { 2012: 379, núm. 3024; } \\
\text { Sánchez y Cañedo, 2012: } \\
\text { 113, núm. 1339) }\end{array}$ & ['Tripas llevan pies'] \\
\hline
\end{tabular}

87 Castañón (1962: 251-252) remite a una carta de Jovellanos a Carlos González Posada, fechada el 14 de enero de 1801 (cfr. el punto 1 en "Refranes mínimos constituidos por tres elementos") y, a continuación, apunta: “También atopa, por afaya. Cab., en Dic. Folk. Ast., I, 185-6, pone cuento como ejemplo". En otro lugar, el mismo autor (1981: 266) traduce faya como 'halla' y vuelve a apuntar: "Ya se lo dijo Jovellanos a su amigo el canónigo González Posada".

88 "El que ahorra tiene".

89 "Refiriéndose a Rioseco, de Sobrescobio". 


\section{Referencias bibliográficas}

Álvarez Fernández-Cañedo, J. (1963) El habla y la cultura popular de Cabrales, Madrid, CSIC.

Amades, J. (1982³) Folklore de Catalunya. Cançoner, Vol. II, Barcelona, Selecta.

Castañón, L. (1959) «Ciento veinte refranes asturianos», Revista de Dialectología y Tradiciones Populares, 15, 449-456.

Castañón, L. (1962) Refranero asturiano, Oviedo, Diputación de Oviedo.

Castañón, L. (1963) «Refranero asturiano (apéndice)», Boletín del Real Instituto de Estudios Asturianos, 49, 251-280.

Castañón, L. (1965) «Segundo apéndice al refranero asturiano», Boletín del Real Instituto de Estudios Asturianos, 54, 73102.

Castañón, L. (1981) «Refranero asturiano», Rodríguez MuÑoz, J. (dir.). Enciclopedia temática de Asturias. Folklore (vol. 9), Gijón, Silverio Cañada, 255-268.

Cervantes, M. de (2015 [1605-1615]) L'inxeniosu fidalgu Don Quixote de La Mancha (versión asturiana de SuÁrez García, P.), Uviéu, Laria [2 vols.].

Correas Martínez, M. y Gargallo Gil, J. E. (2003) Calendario romance de refranes, Barcelona, Edicions de la Universitat de Barcelona.

DCVB = Alcover, A. y Moll, F. de B. (1930-1962) Diccionari català-valencià-balear, Palma de Mallorca, Editorial Moll [10 vols.]. Consultable en línea: http://dcvb.iecat.net/

DLE $=$ Real Academia Española $\left(2014^{23}\right)$ Diccionario de la lengua española. Consultable en línea: http://dle.rae.es/?id=DgIqVCc.

DGLA = García Arias, X. LL. (2002) Diccionario General de la Lengua Asturiana, Oviedo, Editorial Prensa Asturiana S.A. / La Nueva España. Consultable en línea: http://mas.lne.es/diccionario/.

Etхabe, R. (2001) Gran diccionario de refranes, Barcelona, Spes.

FARNÉs, S. (1992-1998) Paremiologia catalana comparada, Barcelona, Columna [8 vols.]. 
Fernández («Coronas, Fernán») G. (1984) Rimas y refranero, Oviedo, Principado de Asturias (Consejería de Educación, Cultura y Deportes).

Ferro Ruibal, X. (1995) Refraneiro galego básico, Vigo, Galaxia.

Fontana, J. (2014) «Algo va de Stan a Pedro. Parèmies populars a les traduccions romaneses integrals del Quijote» (Tesis de doctorado), Universitat de Barcelona. Consultable en línea: http:// diposit.ub.edu/dspace/handle/2445/57803.

García García, L. (1976) «Santos y fiestas en el refranero astur», Boletín del Real Instituto de Estudios Asturianos, 88-89, 535563.

Gargallo Gil, J. E. (2010) «Refranes del calendario y meteorológicos en el Diccionario General de la Lengua Asturiana (DGLA)», Lletres Asturianes (Homenaxe al Profesor Xosé Lluis García Arias), 177-193.

Gargallo Gil, J. E. y Torres Torres, A. (2009) «Caracterización popular de febrero en la paremiología romance a partir de los materiales del Proyecto BADARE», Paremia, 18, 141-152.

Iribarren, J. M. (19744) El porqué de los dichos, Madrid, Aguilar.

Jovellanos, G. M. de (1986) Obras completas III: Correspondencia (Julio 1794 - Marzo 1801), Oviedo, Centro de estudios del siglo xvirI e Ilustre Ayuntamiento de Gijón.

Jovellanos, G. M. de (1992) Diario, Barcelona, Planeta.

Lapucci, C. (2007) Dizionario dei proverbi italiani, Milano, Mondadori.

Machado, J. P. (2011 $)$ O grande livro dos proverbios, Alfragide, Casa das Letras.

Martínez Kleiser, L. (1995 [1953]) Refranero general ideológico español, Madrid, Librería y Casa Editorial Hernando, S.A.

Martinis, M. (2010) Proverbi del Friuli, Udine, FVG spa [2 vols.].

Martino Ruz, X. (2008) Refraneru temáticu asturianu, Xixón, Picu Urriellu.

Montreynaud, F.; Pierron, A. y Suzzoni, F. (1993) Dictionnaire de proverbes et dictons, Paris, Le Robert. 
Ostermann, V. (1995) Proverbi friulani (raccolti dalla viva voce del popolo), Udine, Del Bianco Editore.

PARÉs, A. (2000) Tots els refranys catalans, Barcelona, Edicions 62.

Pérez de Castro, J. L. (1963) «Dialogismos en el Refranero asturiano", Revista de Dialectología y Tradiciones Populares, 19, 116138.

SÁnchez Vicente, X. X. (2008) Diccionariu asturianu-castellanu, Uviéu, Trabe.

Sánchez Vicente, X. X. y Cañedo Valle, X. (2012) Refraneru asturianu, Uviéu, Trabe.

Saralegui y Medina, M. de (1917) Refranero español náutico y meteorológico, Barcelona, Talleres Rieusset.

Schwamenthal, R. y Straniero, M. L. (1991) Dizionario dei proverbi italiani, Milano, Rizzoli.

VenY, J. (1982³) Els parlars catalans, Palma de Mallorca, Raixa.

Viejo Fernández, X. (2012) Paremias populares asturianas (Estudio, clasificación y glosa), Instituto Cervantes, Biblioteca Fraseológica y Paremiológica, Serie «Monografías» n. 4 (https://cvc. cervantes.es/lengua/biblioteca_fraseologica/n4_viejo/paremias_ populares_asturianas.pdf).

VIÑA, D. (20034) Cómo nos explayamos los playos (Decires, refranes y cantarinos de chigre de Gijón), Gijón, vtp editorial. 
